\title{
Reply to 'Economic comments on proposal for a novel cancer drug pricing model'
}

\section{Carin A. Uyl-de Groot and Bob Löwenberg}

Our proposal ${ }^{1}$ identified the key variables in the cost-price calculation of innovative cancer drugs and offered an algorithm for the calculation of a fair price for these drugs. In a correspondence on this article, Nuijten and Vis (Economic comments on proposal for a novel cancer drug pricing model. Nat. Rev. Clin. Oncol. https://doi. org/10.1038/s41571-018-0083-2)2 adhere to the way pharmaceutical companies currently determine the price of anticancer drugs, by applying the principles of free-market economics in the presence of a monopoly. The authors mainly consider the commercial interests of the pharmaceutical companies. Unfortunately, these authors neglect the immense issues created by the current pricing mechanism, including the issues of sustainability and affordability of cancer drugs. Such issues affect all health-care systems, often resulting in patients being unable to access medicines that they urgently need. It is abundantly clear that the existing free-market model does not support the broader use of novel (anticancer) drugs - and thus is in fact harmful to patients globally.

With respect to drug development, it is important to note that a considerable amount of public funding is used to support pharmaceutical research and development (R\&D). This contribution is not reflected in the current drug pricing strategy. A reason for this omission, among others, is the lack of traceability of public funds in the patenting and licensing process, which impedes a fair return on public investment ${ }^{3}$. Therefore, a greater level of transparency in the costs of R\&D is clearly warranted.

With a $68 \%$ increase in the incidence of cancer expected to occur by 2030, a transformation to a new approach to cancer drug pricing is urgently needed. The model that we proposed deliberately intends to serve all stakeholders, including the pharmaceutical industry. Ceasing to defend the current status quo surrounding drug pricing is an important step towards this goal. We encourage all stakeholders to proactively combine efforts to create a more sustainable balance between social and economic entrepreneurship that incentivizes meaningful innovation and provides patients with the highest possible level of access to novel agents.

Carin A. Uyl-de Groot ${ }^{1,2 *}$ and Bob Löwenberg ${ }^{3}$ 'Erasmus School of Health Policy \& Management, Erasmus University Rotterdam, Rotterdam, Netherlands.

${ }^{2}$ Institute for Medical Technology Assessment, Erasmus University Rotterdam, Rotterdam, Netherlands. ${ }^{3}$ Department of Hematology, Erasmus University Medical Center, Rotterdam, Netherlands. *e-mail: uyl@eshpm.eur.nl https://doi.org/10.1038/s41571-018-0084-1

1. Uyl-de Groot, C. A. \& Löwenberg, B. Sustainability and affordability of cancer drugs: a novel pricing model. Nat. Rev. Clin. Oncol. 15, 405-406 (2018).

2. Nuijten, M. J. C. \& Vis, J. Economic comments on proposal for a novel cancer drug pricing model. Nat. Rev. Clin. Oncol. https://doi.org/10.1038/ s41571-018-0083-2 (2018).

3. European Parliament. European Parliament resolution of 2 March 2017 on EU options for improving access to medicines. European Parliament http://www. europarl.europa.eu/sides/getDoc.do?pubRef=-//EP// TEXT+TA+P8-TA-2017-0061+0+DOC+XML+VO//EN (2018).

\section{Competing interests}

C.A.U.-d.G. has received unrestricted grants for research within the Erasmus University from Amgen, Astellas, AstraZeneca, Bayer, Boehringer Ingelheim, Celgene, Genzyme, Gilead, Janssen-Cilag, Merck, Roche, and Sanofi. B.L. has received personal fees from Agros Pharmaceuticals, Astellas, ASTEX, Celgene, Clear Creek Bio, F. Hoffman-La Roche, Novartis, and Seattle Genetics. 